\title{
Assessment of the quality of anticoagulation management with warfarin in a tertiary care center
}

\author{
Monirah A. Albabtain, MSc, Maha M. Alharthi, BSc, Khalid Dagriri, MD, Amr A. Arafat, MD, Esraa Ayrout, PharmD, \\ Yahya Alhebaishi, MD, Ahmed AlFagih, MD.
}

\begin{abstract}

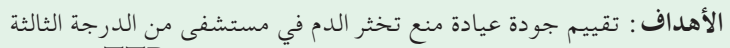

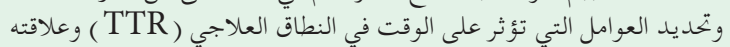
بالمضاعفات المختلفة.

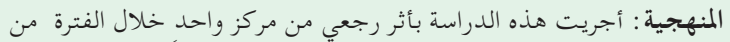

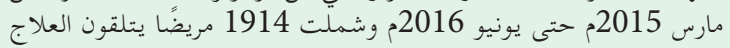

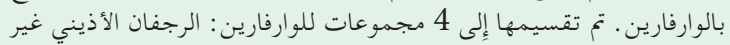

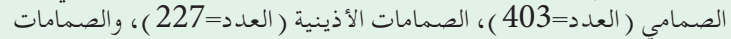
الاصطناعية ( العدد= 700 7 ) ، والانسد اد الوريدي أو أو الرئوي ( العدد= (584 ) والعات ).

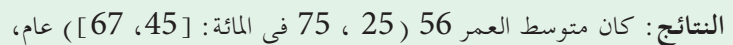

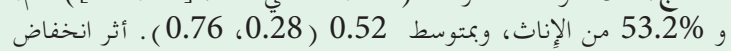

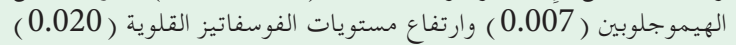

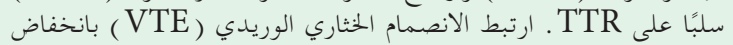

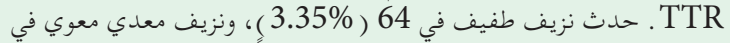

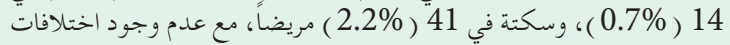

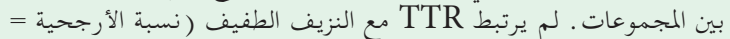

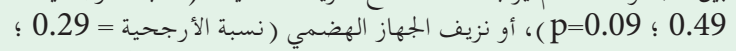

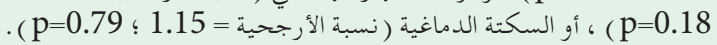

الخخلاصة : تعكس تجربة الحياة الو اقعية للتحكم في منع تخثر الدم، ينفق مرضانا

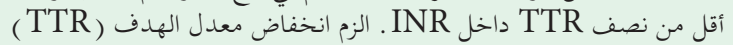

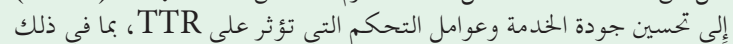

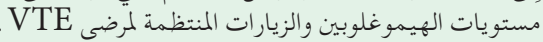

Objectives: To evaluate the quality of an anticoagulation clinic in a tertiary hospital and identified factors affecting the time in the therapeutic range (TTR) and its relation to different complications.

Methods: This single-center retrospective study conducted between March 2015 and June 2016 included 1914 patients receiving warfarin therapy. They were divided into 4 warfarin indication groups: non-valvular atrial fibrillation (AF) $(\mathrm{n}=403)$, valvular AF $(n=227)$, prosthetic valves $(n=700)$, and venous or pulmonary embolism $(\mathrm{n}=584)$.

Results: The median age was 56 (25th, 75 th percentiles: $[45,67])$ years, and $53.2 \%$ were female. The median TTR was $0.52(0.28,0.76)$. Low hemoglobin $(0.007)$ and high alkaline phosphatase (0.020) levels negatively affected the TTR. Venous thromboembolism (VTE) was associated with low TTRs. Minor bleeding occurred in $64(3.35 \%)$, gastrointestinal bleeding in $14(0.7 \%)$, and stroke in $41(2.2 \%)$ patients, with no inter-group differences. The TTR was not associated with minor bleeding (odds ratio $[\mathrm{OR}]=0.49 ; p=0.09$ ), gastrointestinal bleeding $(\mathrm{OR}=0.29 ; p=0.18)$, or stroke $(\mathrm{OR}=1.15 ; p=0.79)$.

Conclusion: Reflecting the real-life experience of anticoagulation control, our patients spend less than half the TTR within the INR. The low target TTR mandates the need to improve service quality and control factors affecting the TTR, including hemoglobin levels and regular visits for patients with VTE.

Keywords: warfarin, anticoagulation, time in therapeutic range

Saudi Med J 2020; Vol. 41 (11): 1245-1251 doi: 10.15537/smj.2020.11.25456

From the Department of Pharmacy (Albabtain, Alharthi), Department of Cardiology (Dagriri, Alhebaishi, AlFagih), Department of Adult Cardiac Surgery (Arafat), Prince Sultan Cardiac Center; from the College of Pharmacy (Ayrout), AlMaarefa University, Riyadh, Kingdom of Saudi Arabia, and from the Department of Cardiothoracic Surgery (Arafat), Tanta University, Tanta, Egypt.

Received 6th July 2020. Accepted 30th September 2020.

Address correspondence and reprint request to: Dr. Monirah $A$. Albabtain, Department of Pharmacy, Prince Sultan Cardiac Center, Riyadh,Kingdom ofSaudi_Arabia.E-mail:muneera_2004@yahoo.com ORCID ID: https://orcid.org/0000-0001-5163-5987

Disclosure. Authors have no conflict of interests, and the work was not supported or funded by any drug company. 
$\mathrm{T}$ hrombosis prevention is a top priority in managing patients with a high risk of thromboembolic events, such as patients with atrial fibrillation (AF), valvular prostheses, and venous or pulmonary embolism venous thromboembolism (VTE). ${ }^{1,2}$ The vitamin $\mathrm{K}$ antagonist warfarin is widely used compared to non-vitamin $\mathrm{K}$ antagonist oral anticoagulant (NOAC) agents, especially for elders and patients with comorbidities. ${ }^{3}$ A major problem of warfarin therapy is the narrow therapeutic index that requires close monitoring of the international normalized ratio (INR). Maintaining INR values within a narrow target range (INR: 2.0-3.0) requires frequent blood tests to ensure the safety and efficacy of warfarin used. ${ }^{4}$ Maximizing the time in the therapeutic range (TTR) within the optimal INR range provides the greatest benefit for the prevention of embolic or thrombotic events and avoidance of severe side effects. ${ }^{5,6}$ The TTR is a good indicator of anticoagulation control and the best predictor for patients' quality outcomes. ${ }^{6}$

The target TTR in clinical trials may be different than the target TTR achieved in community practice. The Thrombosis Canada Guidelines State that good INR control is defined arbitrarily as a TTR $>60 \% .^{5}$ Low TTRs reflect poor anticoagulation control and are associated with thromboembolic or bleeding events. High TTRs provide a better quality of life and health outcomes with fewer adverse events. ${ }^{7}$

Few studies have examined the quality of anticoagulation clinics in high-load centers in our region. We conducted this study to evaluate the quality of an anticoagulation clinic in a tertiary hospital and identify factors affecting the TTR and its relation to different complications.

Methods. This was a single-center, retrospective cohort study conducted at Prince Sultan Military Medical City, Riyadh, Kingdom of Saudi Arabia (KSA) from March 2015 to June 2016. We included patients who were followed up for warfarin therapy at the outpatients' clinic $(\mathrm{n}=1914)$. The patients were divided into 4 groups according to the indication of warfarin: non-valvular AF $(n=403)$, valvular AF $(n=227)$, prosthetic valves $(\mathrm{n}=700)$, and venous or pulmonary embolism $(n=584)$. All patients who presented to the outpatient clinic during the study period were included. Patients who had INR control for a procedure or during the hospitalization were excluded.

Anticoagulation monitoring. Patients were followed in the outpatient clinic by the cardiologists, cardiac surgeons and internists. Follow-up visits were scheduled routinely each 2-3 months and patients with uncontrolled INR required more follow-up visits. International normalized ratio testing was carried out for all patients in the clinic laboratory during the outpatient visit.

We obtained 31547 INR readings with an average of 16 readings per patient during the study period. The therapeutic ranges were calculated using the Rosendaal method (taking the number of INRs within the target range divided by the total number of INRs during the selected time interval). ${ }^{6}$ The INR was tested using the CoaguChek ${ }^{\oplus}$ XS system (Roche, Indianapolis, IN, USA).

Data collection and study outcomes. We extracted the patients' data from the hospital electronic medical records. Baseline data included age, gender, associated comorbidities, and baseline laboratory investigations reported at the initial visit at the time of enrollment. Echocardiographic data, including the ejection fraction, were recorded. All concomitant medications at the time of study enrollment were reported with an emphasis on the medications with interactions with warfarin. We followed the patients longitudinally for adverse effects that occurred during warfarin therapy, such as bleeding and stroke. The study outcomes were the quality of anticoagulation control and influencing factors.

Ethical considerations. The study was approved by the local Institutional Review Board, and they waived the need for consent to participate in the study (reference number: R17004). The study was conducted according to principles of Helsinki Declaration.

Statistical analysis. Continuous variables were presented as $25^{\text {th }}, 50^{\text {th }}$ (median) and $75^{\text {th }}$ percentiles, and categorical data was reported as frequencies and percentages. The normality distribution of the quantitative data was assessed using the ShapiroWilk test. Comparisons between multiple groups were performed using one-way analysis of variance with Tukey's post-hoc test for normally distributed continuous variables and the Kruskal-Wallis test with Dunn's test for skewed data. Pearson's chi-squared test or Fisher's exact test was utilized to compare categorical variables as appropriate. Fractional regression analysis was used to identify predictors of poor TTR control. Logistic regression was used to study the associations among the TTR and different complications. The statistical analysis was conducted using the Statistical Package for Social Sciences (SPSS), version 25 (IBM Corp., Armonk, NY, USA).

Results. Among the 1914 patients receiving anticoagulants included in this study, $74 \%$ were living 
within Riyadh. Their median age was $56\left(25^{\text {th }}, 75^{\text {th }}\right.$ percentiles: 45,67 ) years, $20.7 \%$ were 70 years of age or older, and the age varied significantly among the groups; the patients with prosthetic valves and valvular AF were significantly younger than those with non-valvular $\mathrm{AF}$ $(p<0.001)$. Serum creatinine levels were within the normal range in all the groups but were significantly lower in the nonvalvular AF group $(p<0.001)$. The other laboratory data was within normal ranges with slight variations without significant differences. The baseline characteristics are presented in Table 1. The post-hoc test results for significant continuous variables are presented in Table 2.

Factors affecting the TTR. The median TTR in our study was $0.52(0.28-0.76)$. The TTR was not affected by the patients' residence area, age, or gender. Medications such as antiplatelet agents, amiodarone, digoxin, angiotensin-converting enzyme inhibitors/ angiotensin receptor blockers, beta-blockers, diuretics, and statins did not affect the TTR. In contrast, low hemoglobin $(p=0.007)$ and high alkaline phosphatase (ALP), $(p=0.020)$ levels negatively affected the TTR (Table 3). Venous thromboembolism was associated with a lower TTR.

Adverse events. Bleeding was classified according to the International Society of Thrombosis and Hemostasis into 3 categories; minor bleeding, clinically relevant minor bleeding (CRMB) and major bleeding. Minor bleeding was reported in 64 patients (3.35\%), CRMB $(1.57 \%)$, and intracranial bleeding in one patient in the VTE group. Ischemic stroke was reported in 40 patients (2.1\%). Low TTR was not associated with minor bleeding (odds ratio [OR]: $0.49 ; p=0.09$ ), CRMB (OR: $1.06 ; p=0.73$ ), or stroke (OR: $1.21 ; p=0.23$ ). There was no difference among the groups in bleeding (minor bleeding and CRMB). The incidence of stroke was higher among patients with VTE, did not reach statistical significance (Table 4).

Discussion. The TTR has become the most widely accepted and validated method to measure the quality of anticoagulation control and predict adverse events. ${ }^{8}$ The Thrombosis Canada Guidelines (2017) state that good INR control is defined arbitrarily as a TTR $>60 \% .{ }^{5}$ The updated chest guidelines and expert panel report (2018) recommend a target TTR $\geq 70 \%$ when adjusting the dose of warfarin to achieve the highest quality of anticoagulation control, and TTRs $<65 \%$ require therapeutic intervention. ${ }^{7}$ This study showed that patients receiving warfarin for different indications had TTRs below the recommended level for optimal anticoagulation control, with a median TTR of $52 \%$. The TTR in this study was comparable to that found in other studies that showed low TTRs including the global anticoagulation registry in the FIELD-AF registry $(31.1 \%)$ and other studies conducted in developing countries. ${ }^{3,6,9-16}$ A higher mean TTR of $65 \pm 20$ was reported in the ORBIT-AF registry in the United States of America (USA), as well as a TTR of $\geq 60 \%$ found in a study in Japanese patients. ${ }^{17,18}$ The difference between our studies and others is that our patient population included a wider range of warfarin indications that were not only limited to AF. This, in turn, led to the ability to assess the TTR in a different range of indications.

Our hospital is a tertiary-care governmental institution that has a large load of patients visiting the anticoagulation clinic daily. This high patient number may affect TTR findings in several ways. Anticoagulation clinic appointments are limited in relation to patients' numbers; therefore, close follow-up may not be feasible for all patients. Additionally, several patients reside in remote areas, and these patients may skip their anticoagulation appointments if they are not scheduled with their other clinic visits.

As warfarin has a wide variety of interactions, it is crucial to advise patients about the potential drug interactions to avoid potential harm. Despite the numerous interactions of warfarin, other concomitant drugs do not seem to affect the TTR. The unique inherited culture of our community concerning the use of herbal remedies, especially those with evidencebased reports like ginger, chamomile, garlic, green tea, curcuma, and fenugreek, may place patients at a high risk of warfarin- and herbal remedy-associated interactions, thus affecting both efficacy and safety. ${ }^{19}$ Although this variable was not documented, physicians at our hospital remain committed to providing routine counseling against herbal remedy consumption.

We evaluated factors affecting the TTR. Low hemoglobin levels, high ALP levels, and the use of warfarin for a VTE indication were found to be associated with poor TTR control. PoorTTR in previous studies was affected by different factors: age, gender, socioeconomic status, medical comorbidities, and polypharmacy. ${ }^{5}$ Results from the VARIA study indicate that advanced age is a predictor of a low TTR. ${ }^{20}$ Heart failure has been shown previously to be an important factor that affects the quality of warfarin therapy. ${ }^{21,22}$ Nelson et $\mathrm{al}^{23}$ showed that diabetes, heart failure, and previous stroke are associated with low TTRs. In a study performed in Kuwait, the female gender was associated with poor TTRs; another study in Kingdom of Saudi 
Arabia showed poor anticoagulation control in patients with AF and higher CHADS2 scores. ${ }^{9,10}$

The TTR, which reflects the anticoagulation quality control, is affected by different patient characteristics. In this study, we found that age did not affect the TTR, which can be explained by good compliance of patients receiving warfarin. Our findings suggested that patients with low hemoglobin levels will have less effective anticoagulation management, which indicates that patients receiving warfarin therapy should maintain strict control of their hemoglobin levels.

Patients in the VTE group were found to have the lowest TTRs, and this may be explained by more

Table 1 - Demographic and clinical characteristics of patients according to the indication $(\mathrm{N}=1914)$.

\begin{tabular}{|c|c|c|c|c|c|c|}
\hline Variables & Total & $\begin{array}{c}\text { N-valvular } \\
(n=403)\end{array}$ & $\begin{array}{l}\text { Valvular } \\
(\mathrm{n}=227)\end{array}$ & $\begin{array}{l}\text { Metallic } \\
(\mathrm{n}=700)\end{array}$ & $\begin{array}{c}\text { VTE } \\
(\mathbf{n}=584)\end{array}$ & $P$-value \\
\hline Age, (years) & $56(45,67)$ & $68(58,76)$ & $61(51,70)$ & $53(44,60)$ & $50(37,62)$ & $<0.001$ \\
\hline Weight, (Kg) & $77(66,89)$ & $77(66,90)$ & $75(65,87)$ & $76(66,88)$ & $77(68,90)$ & 0.269 \\
\hline \multicolumn{7}{|l|}{ Patient residence } \\
\hline Inside Riyadh & $1417(74.0)$ & $299(74.2)$ & $173(76.2)$ & $492(70.3)$ & $453(77.6)$ & 0.024 \\
\hline Outside Riyadh & $497(26.0)$ & $104(25.8)$ & $54(23.8)$ & $208(29.7)$ & $131(22.4)$ & \\
\hline Female & $990(51.7)$ & $187(46.4)$ & $162(71.4)$ & $338(48.3)$ & $303(51.9)$ & $<0.001$ \\
\hline \multicolumn{7}{|l|}{ Comorbidities } \\
\hline Hypertension & $1137(59.4)$ & $333(82.6)$ & $156(68.7)$ & $367(52.4)$ & $281(48.1)$ & $<0.001$ \\
\hline Uncontrolled HTN & $115(6.0)$ & $49(12.2)$ & $7(3.1)$ & 30 & $29(5.0)$ & \\
\hline $\mathrm{CAD}$ & $388(20.3)$ & $141(35.0)$ & $38(16.7)$ & $80(11.4)$ & $129(22.1)$ & \\
\hline Diabetes & $740(38.7)$ & $242(60.0)$ & $102(44.9)$ & $191(27.3)$ & $205(35.1)$ & \\
\hline $\mathrm{CHF}$ & $145(7.6)$ & $51(12.7)$ & 21 & $36(5.1)$ & $37(6.3)$ & \\
\hline Dyslipidemia & $516(27.0)$ & $149(37.0)$ & $61(26.9)$ & $133(19.0)$ & $173(29.6)$ & \\
\hline \multicolumn{7}{|l|}{ Laboratory values } \\
\hline Baseline INR (n=1907) & $2.4(1.9,3)$ & $2.2(1.7,2.7)$ & $2.2(1.8,3)$ & $2.8(2.3,3.3)$ & $2.2(1.8,2.7)$ & $<0.001$ \\
\hline Hemoglobin ( $\mathrm{n}=1564)$ & $12.6(11.1,14.1)$ & $12.6(11.2,14.1)$ & $12.5(10.9,13.4)$ & $12.6(11.3$ & $12.6(10.9,14.1)$ & 0.227 \\
\hline Hematocrit $(n=1560)$ & $0.387 \pm 0.06$ & $0.391 \pm 0.06$ & $0.380 \pm 0.06$ & 14.1) & $0.387 \pm 0.06$ & 0.252 \\
\hline ALT $(n=1504)$ & $18(13,26)$ & $17(12,24)$ & $18(13,25)$ & $0.387 \pm 0.06$ & $19(13,28)$ & 0.038 \\
\hline $\operatorname{ALP}(n=1522)$ & $81(64,104)$ & $82(64,105)$ & $82(66,105)$ & $19(14,27)$ & $79(63,102)$ & 0.635 \\
\hline Serum creatinine $(n=1573)$ & $76(60,99)$ & $88.5(68,117)$ & $73(60,91.5)$ & $83(64.3,105)$ & $71(55,94)$ & $<0.001$ \\
\hline Creatinine clearance $(\mathrm{n}=1554)$ & $95(67.8,127.2)$ & $76(51,101)$ & $85.5(67,110)$ & $\begin{array}{r}75(61,91) \\
102(73,131.3)\end{array}$ & $106.5(76,144)$ & $<0.001$ \\
\hline \multicolumn{7}{|l|}{ Echocardiography } \\
\hline $\mathrm{EF}(\mathrm{n}=1736)$ & $55(45,55)$ & $55(45,55)$ & $55(50,55)$ & $55(50,55)$ & $55(35,55)$ & $<0.001$ \\
\hline Apical aneurysm $(\mathrm{n}=1735)$ & $28(1.5)$ & $4(1.0)$ & 0 & $1(0.1)$ & $23(3.9)$ & \\
\hline LV clot $(\mathrm{n}=1734)$ & $84(4.4)$ & $3(0.7)$ & $2(0.9)$ & $3(0.4)$ & $76(13.0)$ & \\
\hline \multicolumn{7}{|l|}{ Medications } \\
\hline ACE inhibitors & $517(27.0)$ & $149(37.0)$ & $53(23.3)$ & $178(25.4)$ & $137(23.5)$ & $<0.001$ \\
\hline Amiodarone & $58(3.0)$ & $22(5.5)$ & $13 \quad(5.7)$ & $10 \quad(1.4)$ & $13(2.2)$ & \\
\hline Anti-platelets & $862(45.0)$ & $198(49.1)$ & $89(39.2)$ & $359(51.3)$ & $216(37.0)$ & \\
\hline $\mathrm{ARB}$ & 347 (18.1) & $115(28.5)$ & $55(24.2)$ & $106(15.1)$ & $71(12.2)$ & \\
\hline Beta blockers & $1168(61.0)$ & $311(77.2)$ & $182(80.2)$ & $465(66.4)$ & $210(36.0)$ & \\
\hline Digoxin & $309(16.1)$ & $83(20.6)$ & $85(37.4)$ & $122(17.4)$ & $19 \quad(3.3)$ & \\
\hline Diuretics & $783(40.9)$ & $221(54.8)$ & $140(61.7)$ & 272 (38.9) & $150(25.7)$ & \\
\hline Statin & $975(50.9)$ & 277 (68.7) & $129(56.8)$ & $293(41.9)$ & $276(47.3)$ & \\
\hline PPI & $935(48.9)$ & $242(60.0)$ & $128(56.4)$ & $303(43.3)$ & $262(44.9)$ & \\
\hline
\end{tabular}

Values are presented as number and percentage (\%). HTN: hypertension, CAD: coronary artery disease, CHF: congestive heart failure, INR: international normalized ratio, ALT: alanine aminotransferase, ALP: alkaline phosphatase, EF: ejection fraction, LV: left ventricle, ACE: angiotensinconverting enzyme, ARB: angiotensin II receptor blockers, PPI: proton pump inhibitors. Continuous data are presented as median $\left(25^{\text {th }}-75^{\text {th }}\right.$ percentiles) and categorical data as number and percent. 
Table 2 - Pairwise multiple comparison post-hoc test results for non-normally distributed continuous variables.

\begin{tabular}{|c|c|c|c|c|}
\hline Variable & G1 & G2 & G3 & G4 \\
\hline Age & $\begin{aligned} \mathrm{G} 1-\mathrm{G} 2 & =0.001 \\
\mathrm{G} 1-\mathrm{G} 3 & =<0.001\end{aligned}$ & $\begin{aligned} \text { G2-G3 } & =<0.001 \\
\text { G2-G4 } & =<0.001\end{aligned}$ & G3-G4 = 0.960 & G4-G1 $=<0.001$ \\
\hline INR at enrollment & $\begin{aligned} \mathrm{G} 1-\mathrm{G} 2 & =0.287 \\
\mathrm{G} 1-\mathrm{G} 3 & =<0.001\end{aligned}$ & $\begin{aligned} \mathrm{G} 2-\mathrm{G} 3 & =<0.001 \\
\mathrm{G} 2-\mathrm{G} 4 & =>0.999\end{aligned}$ & G3-G4 $=<0.001$ & G4-G1 $=>0.999$ \\
\hline Alanine transaminase & $\begin{aligned} \mathrm{G} 1-\mathrm{G} 2 & =>0.999 \\
\mathrm{G} 1-\mathrm{G} 3 & =0.028\end{aligned}$ & $\begin{aligned} \text { G2-G3 } & =>0.999 \\
\text { G2-G4 } & =>0.999\end{aligned}$ & G3-G4 = >0.999 & $\mathrm{G} 4-\mathrm{G} 1=0.259$ \\
\hline Creatinine & $\begin{aligned} \mathrm{G} 1-\mathrm{G} 2 & =<0.001 \\
\mathrm{G} 1-\mathrm{G} 3 & =<0.001\end{aligned}$ & $\begin{aligned} \text { G2-G3 } & =>0.999 \\
\text { G2-G4 } & =>0.999\end{aligned}$ & G3-G4 = >0.999 & $\mathrm{G} 4-\mathrm{G} 1=<0.001$ \\
\hline Creatinine clearance & $\begin{aligned} \mathrm{G} 1-\mathrm{G} 2 & =<0.023 \\
\mathrm{G} 1-\mathrm{G} 3 & =<0.001\end{aligned}$ & $\begin{aligned} \mathrm{G} 2-\mathrm{G} 3 & =<0.001 \\
\mathrm{G} 2-\mathrm{G} 4 & =<0.001\end{aligned}$ & $\mathrm{G} 3-\mathrm{G} 4=0.630$ & G4-G1 $=<0.001$ \\
\hline LV EF & $\begin{aligned} \mathrm{G} 1-\mathrm{G} 2 & =0.003 \\
\mathrm{G} 1-\mathrm{G} 3 & =<0.001\end{aligned}$ & $\begin{aligned} \mathrm{G} 2-\mathrm{G} 3 & =>0.999 \\
\mathrm{G} 2-\mathrm{G} 4 & =0.015\end{aligned}$ & G3-G4 $=<0.001$ & $\mathrm{G} 4-\mathrm{G} 1=>0.999$ \\
\hline TTR & $\begin{aligned} \mathrm{G} 1-\mathrm{G} 2 & =0.120 \\
\mathrm{G} 1-\mathrm{G} 3 & =>0.999\end{aligned}$ & $\begin{aligned} \mathrm{G} 2-\mathrm{G} 3 & =0.585 \\
\mathrm{G} 2-\mathrm{G} 4 & =>0.999\end{aligned}$ & $\mathrm{G} 3-\mathrm{G} 4=0.049$ & $\mathrm{G} 4-\mathrm{G} 1=0.005$ \\
\hline $\begin{array}{l}\text { G1: non-valvular A } \\
\text { group, EF: ejection }\end{array}$ & $\begin{array}{l}\text { roup, G2: valvular } \\
\text { tion, EDD: end dia } \\
\text { : pulmonary artery }\end{array}$ & $\begin{array}{l}\text { roup, G3: metallic v: } \\
\text { c dysfunction, ESD: } \\
\text { lic pressure, TTR: t }\end{array}$ & $\begin{array}{l}\text { group, G4: venous } \\
\text { systolic dysfunctio } \\
\text { in therapeutic rang }\end{array}$ & $\begin{array}{l}\text { romboembolism } \\
\text { LV: left ventricle, }\end{array}$ \\
\hline
\end{tabular}

Table 3 - The factors affecting the time in therapeutic range (TTR).

\begin{tabular}{lcc}
\hline TTR & Coef. $(95 \%$ CI $)$ & $P$-value \\
\hline Weight & $-0.001(-0.003-0.001)$ & 0.495 \\
Inside Riyadh & $-0.044(-0.136-0.048)$ & 0.353 \\
Hemoglobin & $0.027(0.007-0.046)$ & 0.007 \\
ALP & $-0.001(-0.002--0.0001)$ & 0.020 \\
Creatinine & $-0.0001(-0.001-0.0001)$ & 0.743 \\
Gender & $0.060(-0.033-0.153)$ & 0.207 \\
Age & $-0.001(-0.004-0.002)$ & 0.576 \\
Valvular AF & $-0.115(-0.252-0.023)$ & 0.102 \\
Prosthetic valve & $-0.058(-0.168-0.052)$ & 0.302 \\
VTE & $-0.156(-0.275--0.038)$ & 0.010 \\
Uncontrolled hypertension & $-0.014(-0.171-0.142)$ & 0.858 \\
CAD & $-0.005(-0.12-0.111)$ & 0.937 \\
Diabetes mellitus & $0.037(-0.05-0.124)$ & 0.402 \\
CHF & $-0.066(-0.221-0.089)$ & 0.402 \\
Ejection fraction & $0.001(-0.004-0.005)$ & 0.810 \\
Apical aneurysm & $-0.302(-0.63-0.026)$ & 0.071 \\
Amiodarone & $-0.116(-0.34-0.107)$ & 0.307 \\
Digoxin & $-0.053(-0.17-0.064)$ & 0.372 \\
ACE inhibitors & $0.040(-0.58-0.138)$ & 0.424 \\
ARBS & $-0.037(-0.144-0.070)$ & 0.502 \\
Beta blockers & $-0.014(-0.112-0.084)$ & 0.778 \\
Diuretics & $0.002(-0.092-0.097)$ & 0.967 \\
Statins & $0.035(-0.06-0.131)$ & 0.470 \\
PPI & $-0.073(-0.158-0.013)$ & 0.096 \\
Antiplatelet & $0.033(-0.054-0.12)$ & 0.453 \\
\hline CI - confidence interval, ALP - alkaline phosphatase, CAD - coronary \\
artery disease, ACE - angiotensin enzyme, CHF - congestive heart failure, \\
ARB - angiotensin receptor blockers, PPI - proton pump inhibitors, VTE \\
\hline \\
\hline
\end{tabular}

acute events in this group that may be affecting their compliance. The significant association between ALP levels and the TTR may be attributed to hepatic insufficiency, which needs further investigation.

Although there are interactions between some drugs such as amiodarone and digoxin with warfarin, these do not show a significant effect on the TTR. This might be attributed to the awareness of such interactions and protocols to manage such combinations by physicians in the anticoagulation clinic.

Regarding bleeding events, we found no association between the low TTR target and bleeding events. This might be attributed to the low number of events found in our study. Poor TTRs can be explained by the lack of implementation of warfarin dosing protocols in our institution, including clinical pharmacist clinics, which were used later. ${ }^{2}$ These results are of concern because they have a significant economic impact, and previous studies have shown that warfarin is associated with a higher annual outpatient cost in comparison to that of NOAC agents. ${ }^{24}$

Poor TTRs may negatively affect the cost of the treatment, even with no increase in the complication rate. Our study suggests that strict hemoglobin control is essential for patients receiving warfarin therapy, and patients with VTE may benefit from frequent follow-up visits. Further studies are required to confirm our findings. 
Table 4 - Adverse events of warfarin therapy in different indications.

\begin{tabular}{lccccrc}
\hline Adverse events & Total & $\begin{array}{c}\text { Non-valvular } \\
\text { AF }\end{array}$ & $\begin{array}{c}\text { Valvular } \\
\text { AF }\end{array}$ & $\begin{array}{c}\text { Prosthetic } \\
\text { valve }\end{array}$ & VTE & $P$-value \\
\hline Minor bleeding & $64(3.4)$ & $12(3.0)$ & $8(3.5)$ & $29(4.2)$ & $15(2.6)$ & 0.449 \\
CRMB & $30(1.6)$ & $3(0.7)$ & $7(3.1)$ & $12(1.7)$ & $8(1.4)$ & 0.156 \\
Stroke & $40(2.1)$ & $8(2.0)$ & $4(1.8)$ & $9(1.3)$ & $19(3.3)$ & 0.109 \\
\hline \multicolumn{7}{c}{ Values are expressed as number and percentage (\%). } \\
\multicolumn{7}{c}{ AF: atrial fibrillation, CRMB: clinically relevant clinical bleeding, VTE: venous thromboembolism } \\
\hline
\end{tabular}

Study limitations. Our study was a single-tertiarycenter study with a retrospective design that had inherent biases. Several factors that might affect the TTR were not recorded, such as the use of herbal remedies and education level of the patients. Additionally, the lack of time and resources for patient counseling may have also affected the TTR outcomes. As a drawback of the retrospective design, patients' compliance could not be assessed.

In conclusion, our study represents a real-life experience of anticoagulation control. Our patients spend less than half the TTR within the INR. The low target TTR mandates the need to improve the quality of the service and control factors affecting the TTR, such as hemoglobin levels and close follow-up for patients with VTE. Poor TTR control suggests the shifting of eligible patients to direct oral anticoagulants if possible.

Acknowledgment. The authors gratefully acknowledge the following individuals for their contribution in collecting the data for this project: Mr. Hasan Ashmawi, for his role in generating the INR data from the system. We would also like to thank Editage (https://www.editage.com/) for English language editing.

\section{References}

1. Caldeira D, Cruz I, Morgado G, Stuart B, Gomes C, Martins C, et al. Evaluation of time in therapeutic range in anticoagulated patients: a single-center, retrospective, observational study. BMC Res Notes 2014; 7: 891.

2. Wigle P, Hein B, Bloomfield HE, Tubb M, Doherty M. Updated guidelines on outpatient anticoagulation. Am Fam Physician 2013; 87: 556-566.

3. Zhu J, Alexander GC, Nazarian S, Segal JB, Wu AW. Trends and variation in oral anticoagulant choice in patients with atrial fibrillation, 2010-2017. Pharmacotherapy 2018; 38: 907-920.

4. Hirsh J, Fuster V, Ansell J, Halperin JL. American heart association/American college of cardiology foundation guide to warfarin therapy. Circulation 2003; 107: 1692-1711.

5. Gateman D, Trojnar ME, Agarwal G. Time in therapeutic range: warfarin anticoagulation for atrial fibrillation in a communitybased practice. Can Fam Physician 2017; 63: e425-e431.

6. Farsad BF, Abbasinazari M, Dabagh A, Bakshandeh $\mathrm{H}$. Evaluation of time in therapeutic range (TTR) in patients with non-valvular atrial fibrillation receiving treatment with warfarin in Tehran, Iran: a cross-sectional study. J Clin Diagn Res 2016; 10: FC04-FC06.
7. Lip GYH, Banerjee A, Boriani G, Chiang CE, Fargo R, Freedman B, et al. Antithrombotic therapy for atrial fibrillation: CHEST guideline and expert panel report. Chest 2018; 154: 1121-1201.

8. Siddiqui S, DeRemer CE, Waller JL, Gujral JS. Variability in the calculation of time in therapeutic range for the quality control measurement of warfarin. J Innov Card Rhythm Manag 2018; 9: 3428-3434.

9. Alyousif SM, Alsaileek AA. Quality of anticoagulation control among patients with atrial fibrillation: an experience of a tertiary care center in Saudi Arabia. J Saudi Heart Assoc 2016; 28: $239-243$.

10. Zubaid M, Saad H, Ridha M, Mohanan Nair KK, Rashed W, Alhamdan R, et al. Quality of anticoagulation with warfarin across Kuwait. Hellenic J Cardiol 2013; 54: 102-106.

11. Fenta TG, Assefa T, Alemayehu B. Quality of anticoagulation management with warfarin among outpatients in a tertiary hospital in Addis Ababa, Ethiopia: a retrospective cross-sectional study. BMC Health Serv Res 2017; 17: 389.

12. Connolly SJ, Pogue J, Eikelboom J, Flaker G, Commerford P, Franzosi MG, et al. Benefit of oral anticoagulant over antiplatelet therapy in atrial fibrillation depends on the quality of international normalized ratio control achieved by centers and countries as measured by time in therapeutic range. Circulation 2008; 118: 2029-2037.

13. Manji I, Pastakia SD, DO AN, Ouma MN, Schellhase E, Karwa R, et al. Performance outcomes of a pharmacist-managed anticoagulation clinic in the rural, resource-constrained setting of Eldoret, Kenya. J Thromb Haemost 2011; 9: 2215-2220.

14. Chieffo A, Van Mieghem NM, Tchetche D, Dumonteil N, Giustino G, Van der Boon RM, et al. Impact of mixed aortic valve stenosis on VARC-2 outcomes and postprocedural aortic regurgitation in patients undergoing transcatheter aortic valve implantation: results from the international multicentric study PRAGMATIC (pooled Rotterdam-Milan-Toulouse in collaboration). Catheter Cardiovasc Interv 2015; 86: 875-885.

15. Kılıç S, Çelik A, Çakmak HA, Af̧şin A, Tekkeşin Aİ, Açıksarı G, et al. The time in therapeutic range and bleeding complications of warfarin in different geographic regions of Turkey: a subgroup analysis of WARFARIN-TR Study. Balkan Med J 2017; 34 : 349-355.

16. Hakeem H, Khan AZ, Aziz K, Abbasi A, Haider A, Moiz B, et al. Evaluation of quality of warfarin therapy by assessing patient's time in therapeutic range at a tertiary care hospital in Pakistan. J Pak Med Assoc 2018; 68: 1339-1344.

17. Pokorney SD, Simon DN, Thomas L, Fonarow GC, Kowey $\mathrm{PR}$, Chang $\mathrm{P}$, et al. Patients' time in therapeutic range on warfarin among US patients with atrial fibrillation: results from ORBIT-AF registry. Am Heart J 2015; 170: 141-148. 
18. Inoue H, Kodani E, Atarashi H, Okumura K, Yamashita $\mathrm{T}$, Okuyama Y, et al. Time in therapeutic range and disease outcomes in elderly Japanese patients with nonvalvular atrial fibrillation. Circ J 2018; 82: 2510-2517.

19. Ge B, Zhang Z, Zuo Z. Updates on the clinical evidenced herbwarfarin interactions. Evid Based Complement Alternat Med 2014; 2014: 957362.

20. Rose AJ, Hylek EM, Ozonoff A, Ash AS, Reisman JI, Berlowitz DR. Patient characteristics associated with oral anticoagulation control: results of the veterans affairs study to improve anticoagulation (VARIA). J Thromb Haemost 2010; 8: 2182-2191.

21. Ciurus T, Cichocka-Radwan A, Lelonek M. Factors affecting the quality of anticoagulation with warfarin: experience of one cardiac centre. Kardiochir Torakochirurgia Pol 2015; 12: 334-340.
22. Melamed OC, Horowitz G, Elhayany A, Vinker S. Quality of anticoagulation control among patients with atrial fibrillation. Am J Manag Care 2011; 17: 232-237.

23. Nelson WW, Choi JC, Vanderpoel J, Damaraju CV, Wildgoose $\mathrm{P}$, Fields LE, et al. Impact of co-morbidities and patient characteristics on international normalized ratio control over time in patients with nonvalvular atrial fibrillation. Am J Cardiol 2013; 112: 509-512.

24. Diken AI, Yalçınkaya A, Hanedan MO, Erol ME, Ercen Diken Ö. Rivaroxaban vs. warfarin on extended deep venous thromboembolism treatment: a cost analysis. Phlebology 2018; 33: 53-59. 